\title{
Visions of oppression in asylums
}

\begin{abstract}
Annabelle Dudley and John Gavilan object to a onesided felevision view of asylums and what has replaced them.
\end{abstract}

The title of the Channel 4 documentary Stolen Lives conjured up visions of oppression and denial of human rights, and as a critique of the asylums in the early part of this century it lived up to what it suggested. The programme showed the views of four patients who were residents of Meanwood Park Community Colony outside Leeds. It was set up in 1920 and at the height of its activity catered for 2000 people with learning disability.

The programme illustrated some important concepts concerning the rights of vulnerable people. However it did not make clear that, in the early part of the century, such systems provided a safe environment. This was vital for those with a more severe degree of learning disability, who were open to abuse and exploitation, at a time when community care was non-existent. Before asylums those detained under the 1744 Act were mostly in houses of correction and the rest in poorhouses or workhouses in appalling conditions.

Samuel Wormold was responsible for admissions to Meanwood. He subscribed to the degeneracy theory which reflected the moral feelings of that time. He felt that people with a moral deficiency should be cleared from the streets. This was supported by the 1913 Mental Deficiency Act which divided people into moral defectives, idiots, imbeciles and the feeble-minded.

In his writings Samuel Wormold was quoted as saying, "By allowing to repeat their type, the feeble-minded are increasing the ranks of the degenerate and wastrel classes with disastrous consequences to the entire community". This was little more than a form of eugenics.
With the advent of the 1959 Mental Health Act people were no longer kept in Meanwood against their will. However without community facilities, resettlement did not begin until the early '70s. Maggie Potts, Clinical Psychologist at Meanwood, had some reservations about some of the current methods of resettlement. She argued that resettlement into the community had been dictated by economics, rather than the needs of the individual. She felt that people did not have a choice and that the punitive environment at Meanwood in the past, to a lesser and different degree, continued in some modern placements. She was especially critical of community villages which she implied were run like mini asylums.

This has not been our experience. First. many successful village communities exist such as The Ravenswood Trust in Surrey. Second, choice does exist in resettlement, although in some cases this may be tailored to the special needs of the individual such as challenging behaviour. Third, punishment is not used as a form of behavioural modification. We do not feel the by-product of modern treatments is to curtail individuality, as Ms Potts suggested, reproducing the mistakes of the past. People with severe learning disability are vulnerable and benefit from the degree of structure offered to them in modern placements such as village communities.

If the programme makers had interviewed a wide variety of staff from separate disciplines at Meanwood, they would have found there was more than one opinion on the subject.

ANNABELle Dudley, Research Registrar; and JOHN GAVILAN, Senior Registrar in the Psychiatry of Learning Disability, Guy's Hospital, London SE1 9RT 